\title{
Acupuntura como auxílio diagnóstico para as afecções dentárias em equinos
}

Mariana Marcantonio Coneglian, Pedro Vicente Michelotto Jr

Pontifícia Universidade Católica do Paraná (PUCPR), Curitiba, PR, Brasil

*Autor correspondente

e-mail: mmconeglian@yahoo.com.br

\section{Resumo}

Dentre os problemas que acometem os equinos, pode-se destacar as alterações na cavidade oral, especialmente os problemas dentários. Estes são considerados a terceira causa mais comum de enfermidades clínicas em equinos na América do Norte. No nosso país, entretanto, esse problema ainda é subestimado. Acredita-se que o diagnóstico por pressão de pontos de acupuntura possa auxiliar no diagnóstico das afecções da cavidade oral. Com objetivo de avaliar a confiabilidade do ponto de acupuntura indicativo de afecções na cavidade oral (Cain, 2003) em equinos, foram selecionados 22 equinos, machos e fêmeas, com idade variando de 2,5 a 12 anos. Todos os animais incluídos neste trabalho apresentavam-se saudáveis no momento do exame e estavam sendo utilizados em atividade de esporte (laço comprido). A avaliação por acupuntura foi realizada pelo mesmo avaliador através da pressão em pontos de acupuntura, incluindo o ponto ashi, indicativo de alterações dentárias, como descrito por Cain (2003). Em seguida, realizou-se o exame da cavidade oral através de inspeção e palpação externa e interna. Para isso, os animais foram sedados e um espéculo oral e uma fonte de luz foram utilizados. Realizou-se também uma anamnese com os responsáveis pelos animais com o intuito de identificar possíveis sinais indicativos de dor na cavidade oral durante o exercício ou mastigação. Todas as alterações encontradas foram corrigidas e, após 15 dias, um segundo exame de palpação dos pontos de acupuntura e uma nova anamnese foram realizados. Todos os exames foram realizados pelo mesmo avaliador, porém foram registrados por filmagens e fotografia para conferência de um segundo examinador. Os dados são apresentados de forma descritiva. Todos os animais investigados apresentavam algum tipo de alteração odontológica (presença de pontas excessivas de esmalte acompanhadas ou não de ulcerações na mucosa, presença de dente de lobo ou alterações na mesa oclusal como degraus, ganchos ou rampas), e desses 22 animais, 18 (81\%) apresentaram sensibilidade pronunciada no ponto ashi relacionado à síndrome odontológica. Dezessete $(77,27 \%)$ dos animais investigados 
apresentaram na anamnese algum indicativo de desconforto durante a mastigação ou durante a utilização de freio. Quinze dias após o tratamento dentário todos os proprietários relataram desaparecimento dos sinais indicativos de dor na cavidade oral e mesmo aqueles que não tinham queixas iniciais relataram melhor desempenho dos animais durante os exercícios, o que demonstra a efetividade do tratamento odontológico realizado. A reavaliação pela pressão de pontos de acupuntura revelou que a sensibilidade no ponto ashi relacionado à cavidade oral desapareceu em 15 animais (83,3\%). Desta forma, é possível concluir que a inclusão da avaliação deste ponto no exame de rotina de equinos pode facilitar a identificação de animais que sofram com alterações odontológicas e, consequentemente, ampliar o número de animais que recebe tratamento adequado.

Palavras-chave: Odontologia equina. Acupuntura. Medicina Tradicional Chinesa. 